\section{FRI0613 THERAPEUTIC STRATEGIES AND SURVIVAL IN PATIENTS WITH INTERSTITIAL PNEUMONIA WITH AUTOIMMUNE FEATURES}

Marco Sebastiani ${ }^{1}$, Caterina Vacchi ${ }^{1}$, Lisa De Pasquale ${ }^{1}$, Stefania Cerri ${ }^{2}$, Giulia Cassone ${ }^{1,3,4}$, Giovanni Della Casa ${ }^{5}$, Martina Garofalo ${ }^{2}$, Carlo Salvarani ${ }^{1,3}$, Andreina Manfredi ${ }^{1}{ }^{1}$ University of Modena and Reggio Emilia, Azienda Ospedaliero-Universitaria Policlinico di Modena, Chair and Rheumatology Unit, Modena, Italy, ${ }^{2}$ University of Modena and Reggio Emilia, Azienda OspedalieroUniversitaria Policlinico di Modena, Respiratory Disease Unit, Modena, Italy; ${ }^{3}$ IRCCS Arcispedale Santa Maria Nuova, Azienda Unità Sanitaria Locale-IRCCS di Reggio Emilia, Rheumatology Unit, Reggio Emilia, Italy; ${ }^{4}$ University of Modena and Reggio Emilia, Clinical and Experimental Medicine PhD Program, Modena, Italy; ${ }^{5}$ University of Modena and Reggio Emilia, Azienda Ospedaliero-Universitaria Policlinico di Modena, Radiology Unit, Modena, Italy

Background: Recently the term "interstitial pneumonia with autoimmune features" (IPAF) has been proposed to identify patients with interstitial lung disease and autoimmune characteristics, not fulfilling the criteria for specific connective tissue diseases (CTD). Until now, only few data are available about the clinical and serological features of IPAF patients, their survival and the possible evolution in a CTD.

Objectives: Aim of the study was to investigate the therapeutic choices in IPAF patients, their efficacy and safety.

Methods: Fifty-two patients (mean age at diagnosis $65.5 \pm 11.0$ years, female/male ratio 29/23) were consecutively enrolled and prospectively followed for $45 \pm 31.6$ months.

Data about therapies, disease onset, serological, clinical and therapeutic features, pulmonary function tests and high-resolution computed tomography were periodically repeated. A worsening of lung function was defined as a reduction of $10 \%$ compared to baseline of forced vital capacity (FVC) and diffusion lung capacity of CO (DLCO).

Results: An immunosuppressive therapy was prescribed in 15 patients (namely cyclophosphamide in 4, mycophenolate mofetil in 6 and azathioprine in 6 , respectively), while 6 patients were treated with anti-fibrotic therapies (pirfenidone or nintedanib). Thirty-three patients taken corticosteroids, associated to other drugs in 18 patients, and alone in 15. Finally, no therapies were prescribed in 16 patients. At the end of follow-up FVC remained stable in $35 \%$ of patients, worsened in $50 \%$ and increased in $15 \%$; DLCO remained stable in $25.8 \%$ of patients, worsened in $58.1 \%$ and increased in $16.1 \%$.

Mean survival was $94.2 \pm 8.5$ months, and no differences were recorded according to the kind of therapy, while survival was significantly associated to the lung function at baseline (FVC and DLCO were confirmed to be significantly associated to death at multivariate analysis).

The treatment was generally well tolerated. In 7/15 patients treated with immunosuppressive therapy was recorded at least an adverse event, responsible for the treatment discontinuation only in 3 patients.

Conclusion: The therapeutic strategy in IPAF patients reflects the etherogeneity of the disease. Waiting for specific trial in this population, treatment is empyrical and based on the baseline features of the patients. Despite well tolerated both anti-fibrotic and immunosoppressive therapies seem to not influence the evolution of the disease.

\section{REFERENCES:}

[1] Fischer A, Antoniou KM, Brown KK, eta al. "ERS/ATS Task Force on Undifferentiated Forms of CTD-ILD”. An official European Respiratory Society/American Thoracic Society research statement: interstitial pneumonia with autoimmune features. Eur Respir J. 2015;46:976-87

[2] Ferri C, Manfredi A, Sebastiani M, et al. Interstitial pneumonia with autoimmune features and undifferentiated connective tissue disease: Our interdisciplinary rheumatology-pneumology experience, and review of the literature. Autoimmun Rev. 2016;15:61-70

Disclosure of Interests: None declared

DOI: 10.1136/annrheumdis-2019-eular.3709

\section{FRI0614 CLINICAL AND LABORATORY FEATURES OF MACROPHAGE ACTIVATION SYNDROME IN PATIENTS WITH ADULT STILL'S DISEASE}

Hiroya Tamai, Yuko Kaneko, Tsutomu Takeuchi. Keio University School of Medicine, Division of Rheumatology, Department of Internal Medicine, Tokyo, Japan

Background: Adult Still's Disease (ASD) sometimes develops macrophage activation syndrome (MAS). MAS is a severe, fatal complication, however, little is known about its clinical courses and relation to initial symptoms, diagnosis and treatment.

Objectives: To clarify characteristics of MAS in patients with ASD and identify risk factors for developing MAS.

Methods: Consecutive ASD patients diagnosed with Yamaguchi's criteria in our hospital from April 2012 through September 2017 were retrospectively reviewed. Clinical symptoms, laboratory data and treatment information were collected form their charts. Patients were divided into two groups according to the complication of MAS and analyzed.

Results: Sixty five patients with ASD with available information were enrolled in the analysis. The mean age at ASD onset was 45.7 years old, and female was $81.5 \%$. Among them, 12 patients $(18.5 \%)$ developed MAS during the clinical course. Three patients developed MAS at the same time with the diagnosis of ASD, seven patients after the initiation of glucocorticoid treatment, and two patients at relapse. Five of nine who underwent bone marrow examination proved to be complicated with hemophagocytotic syndrome. The median duration from initial symptoms of ASD to fulfilment of Yamaguchi's criteria was shorter in patients with MAS than those without ( 10.5 days vs 21.0 days, $p=0.077)$. Drug allergy occurred more frequently in patients with MAS $(50.0 \%$ vs $22.6 \%$, $\mathrm{p}=0.056$ ). The maximum levels of ferritin and AST before treatment was higher in patients with MAS than those without (ferritin, $6090 \mathrm{ng} / \mathrm{mL}$ vs $3434 \mathrm{ng} / \mathrm{mL}$, AST $86.5 \mathrm{U} / \mathrm{L}$ vs $68.0 \mathrm{U} / \mathrm{L}$ ), whereas the maximum levels of CRP was lower in patients with MAS $(8.9 \mathrm{mg} / \mathrm{dL}$ vs $15.9 \mathrm{mg} / \mathrm{dL})$. In nine patients who developed MAS after glucocorticoid treatment, white blood cell count decreased by almost half despite moderate to high dose of glucocorticoid, and the level of ALT increased 10-fold and ferritin increased 2-fold at MAS development. However, the levels of CRP at MAS rather decreased before treatment, suggesting the change in CRP did not reflect MAS development.

Conclusion: The incidence of MAS was $18.5 \%$ during the clinical course of ASD. Patients with MAS developed ASD more rapidly than those with out. The ferritin and ALT levels predicted and reflected MAS development, whereas CRP levels was not associated with MAS.

Disclosure of Interests: Hiroya Tamai: None declared, Yuko Kaneko Grant/research support from: Abbvie, Eisai, Speakers bureau: AbbVie, Astellas, Ayumi, Bristol-Myers Squibb, Chugai, Eisai, Eli Lilly, Jansen, Kissei, Pfizer, Sanofi, Takeda, Tanabe-Mitsubishi, UCB, Tsutomu Takeuchi Grant/research support from: Astellas Pharma Inc, Chugai Pharmaceutica Co, Ltd., Daiichi Sankyo Co., Ltd., Takeda Pharmaceutical Co., Ltd., AbbVie GK, Asahikasei Pharma Corp., Mitsubishi Tanabe Pharma Co., Pfizer Japan Inc., Eisai Co., Ltd., AYUMI Pharmaceutical Corporation, Nipponkayaku Co. Ltd., Novartis Pharma K.K., Grant/research support from: AbbVie, Asahi Kasei, Astellas, AstraZeneca, AYUMI, Bristol-Myers Squibb, Chugai, Daiichi Sankyo, Eisai, Eli Lilly Japan, Janssen, Mitsubishi Tanabe, Nippon Kayaku, Novartis, Pfizer Japan Inc, Taiho, Taisho Toyama, Takeda, Teijin, Grant/research support from: Astellas Pharma Inc., Bristol Myers Squibb, Chugai Pharmaceutical Co., Ltd., Mitsubishi Tanabe Pharma Co., Pfizer Japan Inc., Santen Pharmaceutical Co., Ltd. Takeda Pharmaceutical Co., Ltd., Teijin Pharma Ltd., AbbVie GK, Asahi Kasei Pharma Corp., Taisho Toyama Pharmaceutical Co., Ltd., SymBio Pharmaceuticals Ltd., Janssen Pharmaceutical K.K., Celltrion Inc., Nipponkayaku Co. Ltd., and UCB Japan, Consultant for: Astra Zeneca K.K., El Lilly Japan K.K., Novartis Pharma K.K., Mitsubishi Tanabe Pharma Co., Abbivie GK, Nipponkayaku Co.Ltd, Janssen Pharmaceutical K.K., Astellas Pharma Inc., Taiho Pharmaceutical Co. Ltd., Chugai Pharmaceutical Co. Ltd., Taisho Toyama Pharmaceutical Co. Ltd., GlaxoSmithKline K.K., UCB Japan Co. Ltd., Consultant for: AbbVie, Asahi Kasei, Astellas, AstraZeneca, AYUMI, Bristol-Myers Squibb, Chugai, Daiichi Sankyo, Eisai, Eli Lilly Japan, Janssen, Mitsubishi Tanabe, Nippon Kayaku, Novartis, Pfize Japan Inc, Taiho, Taisho Toyama, Takeda, Teijin, Consultant for: Astra Zeneca K.K., Eli Lilly Japan K.K., Novartis Pharma K.K., Mitsubishi Tanabe Pharma Co., Asahi Kasei Medical K.K., AbbVie GK, Daiichi San kyo Co., Ltd., Bristol Myers Squibb, and Nipponkayaku Co. Ltd., Speakers bureau: Astellas Pharma Inc., Bristol Myers Squibb, Chugai Pharmaceutical Co., Ltd., Mitsubishi Tanabe Pharma Co., Pfizer Japan Inc., Santen Pharmaceutical Co., Ltd., Takeda Pharmaceutical Co., Ltd. Teijin Pharma Ltd., AbbVie GK, Asahi Kasei Pharma Corp., Taisho Toyama Pharmaceutical Co., Ltd., SymBio Pharmaceuticals Ltd., Janssen Pharmaceutical K.K., Celltrion Inc., Nipponkayaku Co. Ltd., and UCB Japan, Speakers bureau: AbbVie, Asahi Kasei, Astellas, AstraZeneca, AYUMI, Bristol-Myers Squibb, Chugai, Daiichi Sankyo, Eisai, Eli Lilly Japan, Janssen, Mitsubishi Tanabe, Nippon Kayaku, Novartis, Pfizer Japan Inc, Taiho, Taisho Toyama, Takeda, Teijin, Speakers bureau: AbbVie GK., Bristol-Myers K.K., Chugai Pharmaceutical Co. Ltd., Mitsubishi Tanabe Pharma Co., Pfizer Japan Inc., Astellas Pharma Inc, Diaichi Sankyo Co. Ltd., Eisai Co. Ltd., Sanofi K.K., Teijin Pharma Ltd., Takeda Pharmaceutical Co. Ltd., Novartis Pharma K.K. 
Data represented either as the median (25th-75th percentile) or as the frequency a: MannWhitney test b: Pearson Chi-Square test, CQR, Compliance Questionnaire on

\section{FRI0615 EVALUATION OF COMPLIANCE AND RELATED FACTORS IN COLCHICINE TREATMENT IN FAMILIAL MEDITERRANEAN FEVER PATIENTS}

Emre Tekgoz ${ }^{1}$, Seda Colak ${ }^{1}$, Fatma IIlknur Cinar ${ }^{2}$, Sedat Yilmaz ${ }^{1}$ Muhammet Çınar ${ }^{1} .{ }^{1}$ University of Health Sciences, Gulhane Faculty of Medicine, Department of Internal Medicine, Division of Rheumatology, Ankara, Turkey, ${ }^{2}$ University of Health Sciences, Gulhane Faculty of Nursing, Department of Internal Medicine Nursing, Ankara, Turkey

Background: Familial Mediterranean Fever (FMF) is an autoinflammatory disease requiring long-term treatment. Increasing the compatibility with colchicine treatment in patients with FMF is the first step for preventing amyloidosis. Patients' beliefs about medicines and treatment may affect treatment adherence and treatment success.

Objectives: The aim of this study was to determine adherence to colchicine treatment and related factors in FMF patients. In addition, patients beliefs about colchicine, which are one of the important factors affecting the treatment adherence of patients, were evaluated.

Methods: Total of 179 patients with FMF was included in this study. The demographic and clinical features and MEFV gene mutations were recorded. The treatment adherence of the patients was assessed using by Compliance Questionnaire on Rheumatology (CQR). The Beliefs About Medicines Questionnaire (BMQ-T) was used to assess patient's beliefs about colchicine. The relationship between compliance of treatment and clinical characteristics of patients were assessed.

Results: One hundred thirteen $(63.1 \%)$ of the patients were male. The mean age of patients was $34.5 \pm 12.7$ years and mean delay in diagnosis was $6.7 \pm 8.4$ years. The mean dose of colchicine was $1.37 \pm 0.43$ $\mathrm{mg} /$ day and, the percentage of patients using colchicine regularly was $66.5 \%$. Adherence to treatment was higher in patients with concomitant diseases than those without comorbidities $(p=0.028)$. In addition, treatment compliance was higher in married patients compared to single patients $(p=0.013)$. The colchicine dose used in compatible patients was higher than in non-compatible patients $(p=0.033)$ (Table 1). We also found that as the BMQ-T Specific Necessity scores increased, compliance with treatment increased. On the other hand, as the BMQ-T General Overuse and General Harm scores increased, non-compliance with treatment increased (Table 2).

Table 1. Relationships between socio-demographic and clinical characteristics of patients and CQR score $(\mathrm{n}=179)$

\begin{tabular}{lccc}
\hline Characteristics & \multicolumn{3}{c}{ CQR score } \\
\hline \multicolumn{1}{l}{$\mathbf{2 0 0} \mathbf{n = 2 9}$} & $<\mathbf{8 0 \%} \mathbf{n = 1 5 0}$ & $\mathbf{p}$ \\
\hline Age (years) median (25th-75th percentile) & $37.0(28.5-44.5)$ & $29.0(24.0-44.0)$ & $0.099^{\mathrm{a}}$ \\
Gender (n,\%) & $15(13.3)$ & $98(86.7)$ & $0.164^{\mathrm{b}}$ \\
Male & $14(21.2)$ & $52(78.8)$ & \\
Female & & & \\
Marital status, (n,\%) & $21(22.8)$ & $71(77.2)$ & $\mathbf{0 . 0 1 3 ^ { \mathrm { b } }}$ \\
Married & $8(9.2)$ & $79(90.8)$ & \\
Single/widowed/divorced & $12(26.7)$ & $33(73.3)$ & $\mathbf{0 . 0 2 8 ^ { \mathrm { b } }}$ \\
Comorbidities, (n,\%) & $17(12.7)$ & $117(87.3)$ & \\
Yes & & & \\
No & $3.0(0.5-10.0)$ & $3.0(1.0-9.0)$ & $0.920^{\text {a }}$ \\
Delay of diagnosis (years) & & & \\
Median (25th-75th percentile) & &
\end{tabular}

Rheumatology

Table 2. Beliefs about Medicines Questionnaire Scale Scores in Adherent and Nonadherent Patients.

\begin{tabular}{lcccc}
\hline \multicolumn{5}{c}{ CQR score } \\
\hline Variable & \multicolumn{5}{c}{ Discontinuous } \\
\hline & $\mathbf{8 0}=\mathbf{n}=$ & $<80 \% \mathrm{n}=150$ & $\mathbf{Z}$ & $\mathrm{p}$ \\
BMQ-T-Specific & $4.8(4.1-5.0)$ & $3.8(3.35-4.25)$ & -5.260 & $<$ \\
Necessity & & & & $\mathbf{0 . 0 0 1}$ \\
BMQ-T-Specific Concerns & $2.8(2.2-3.8)$ & $2.8(2.4-3.6)$ & -0.100 & 0.920 \\
BMQ-T-General Overuse & $2.25(1.75-$ & $2.75(2.25-$ & -2.936 & $\mathbf{0 . 0 0 3}$ \\
& $2.63)$ & $3.25)$ & & \\
BMQ-T-General Harm & $1.75(1.38-$ & $2.38(2.0-3.0)$ & -3.212 & $\mathbf{0 . 0 0 1}$ \\
& $2.63)$ & & & \\
\hline
\end{tabular}

Z; Mann-Whitney test, Data represented as median (25th-75th percentile, CQR; Compliance Questionnaire on Rheumatology

Conclusion: In patients with FMF, it is important to evaluate the compliance with the treatment due to the importance of colchicine to prevent amyloidosis that may occur in patients without treatment. As this study shows it is also important to determine patients' beliefs about medicine in terms of their influence on patients' compliance with treatment.

Disclosure of Interests: : None declared

DOI: 10.1136/annrheumdis-2019-eular.3545

\section{FRI0616 ANAKINRA TREATMENT IN RECURRENT PERICARDITIS: SINGLE CENTER EXPERIENCE}

Zeynep Toker Dincer, Osman Corbali, Serdal Ugurlu, Huri Ozdogan. University of Istanbul-Cerrahpasa, Division of Rheumatology, Department of Internal Medicine, Istanbul, Turkey

Background: Recurrent pericarditis (RP), however the etiology is unknown in the majority, may be observed in autoinflammatory diseases such as familial Mediterranean fever (FMF) and tumor necrosis factor receptor-1 associated periodic syndrome (TRAPS). Colchicine has long been used to treat pericarditis related to FMF as well as patients with idiopathic recurrent pericarditis (IRP) (1). Alternative treatments have been reported for cases with colchicine resistant RP.Objectives:

Objectives: The aim is to present our data regarding anakinra treatment in recurrent pericarditis either related to FMF or idiopathic, who are resistant to colchicine.

Methods: Patients who had recieved anakinra with a diagnosis of recurrent pericarditis either idiopathic or secondary to FMF followed in our autoinflammatory disease center between 2014-2018 are evaluated retrospectively. From patients' files, demographic and clinical features, response to other treatment approaches such as NSAID, corticosteroid, colchicine, were evaluated. All patients have been genetically screened for monogenic autoinflammatory diseases (MEFV, TRAPS, MVK, NLRP3, NOD2). Patients who had at least 3 attacks were administered anakinra $100 \mathrm{mg} /$ day. Therapeutic efficacy, as well as side effect profile of anakinra is also assessed.

Results: There were 5 patients ( 3 male and 2 female) with the diagnosis of RP, 1 was related to FMF and 4 were idiopathic. The mean age of

Table 1. Demographic features and treatment response during anakinra therapy

\begin{tabular}{|c|c|c|c|c|c|c|c|c|c|}
\hline $\begin{array}{l}\text { Patient } \\
\text { ID \# }\end{array}$ & Age & Sex & Diagnosis & $\begin{array}{c}\text { Duration of pericarditis } \\
\text { follow-up (mo) }\end{array}$ & Prior medications & $\begin{array}{c}\text { Number of recurrences } \\
\text { before anakinra }\end{array}$ & $\begin{array}{c}\text { Anakinra treatment } \\
\text { duration }(\mathrm{mo})\end{array}$ & $\begin{array}{l}\text { Time to corticosteroid } \\
\text { discontinuation }(\mathrm{mo})\end{array}$ & $\begin{array}{c}\text { Number of recurrences after } \\
\text { daily dose of anakinra }\end{array}$ \\
\hline $1^{*}$ & 23 & $M$ & IRP & 129 & $\begin{array}{c}\text { Colchicine, } \\
\text { NSAIDs, CS, HCQ }\end{array}$ & 6 & 52 & 9 & No \\
\hline 2 & 32 & $\mathrm{~F}$ & IRP & 128 & $\begin{array}{l}\text { Colchicine, } \\
\text { NSAIDs }\end{array}$ & 7 & 4 & NA & No \\
\hline $3^{*}$ & 40 & $\mathrm{~F}$ & IRP & 21 & Colchicine, CS & 6 & 8 & 1 & No \\
\hline 4 & 20 & M & IRP & 11 & Colchicine, CS & 3 & 8 & 2 & No \\
\hline 5 & 25 & M & FMF & 30 & Colchicine, CS & 5 & 15 & 1 & No \\
\hline
\end{tabular}

F: Female, M: Male, CS: Corticosteroid, HCQ: Hydroxychloroquine, NA: Not applicable

*Dose tapering was unsuccessful in these patients 